\title{
To look too closely
}

\section{Scope for improvement.}

\section{Paul Grainger}

The Change Approval Officer, tasked with keeping the computer systems operational, opened the meeting with an edge of annoyance you could shave with. "This extra-ordinary session of Project ERT is to consider the Deep Graphical Department's request for an urgent upgrade to the project's graphics hardware."

"Yes CAO. The Intelligence Department has recently made us aware of an imminent increase in visual surveying requirements."

The CAO sighed with the resignation of a pensioner trying to cross a motorway. "Have you verified the upgrade in the test system?"

"You will understand that we had limited time. This is a reasonably standard upgrade, of which we are generally experienced."

"You fill me with the confidence of a frog in a food-blender. However, the requirement and urgency have been verified. Upgrade approved. Please ensure your back-out plan is more substantial than your resignation.”

The two engineers sat in a room filled with monitors, keyboards and Dilbert cartoons. They helped themselves to a jar of pickled chillies as they watched a TV behind their workstations. "Later, a thrilling debate on where we came from and what it's all about between the octogenarian evolution evangelist Richard Dawkins and Pope Albert. But first to NASA's mission control where they're about to bring a multibillion-dollar telescope array online. Other currencies were involved."

"That's us, Jasper," said one of the engineers.

"This is it, Oddman," said Jasper, sucking the vinegar off a chilli as if it were honey off a bear's paw. "An orbital four-telescope array, huge precision-milled mirrors, gridbased software. We'll be able to see planets, atmospheres, even little aliens." He paused. "Well, maybe not that little."

Oddman swung round to a keyboard and started tapping away. "With what I've done, you'll be able to see up their nostrils, assuming they're standing on their heads, assuming they have heads."

"What have you done?"

Oddman chuckled like a turkey. "I've short cut NASA's CMM level-5 processes, where anything new takes ten years to get in front of a committee, if you're lucky.
During our deployment checks, I'll get the five-scope array we've always wanted; I've rewritten the imaging software; we'll be a hundred times better than anyone could have expected." Jasper's mouth dropped open. Oddman put a chilli in it. "Don't worry dude, it's all discrete components, from disparate locations. No one, not even Agent Mulder, could piece this together."

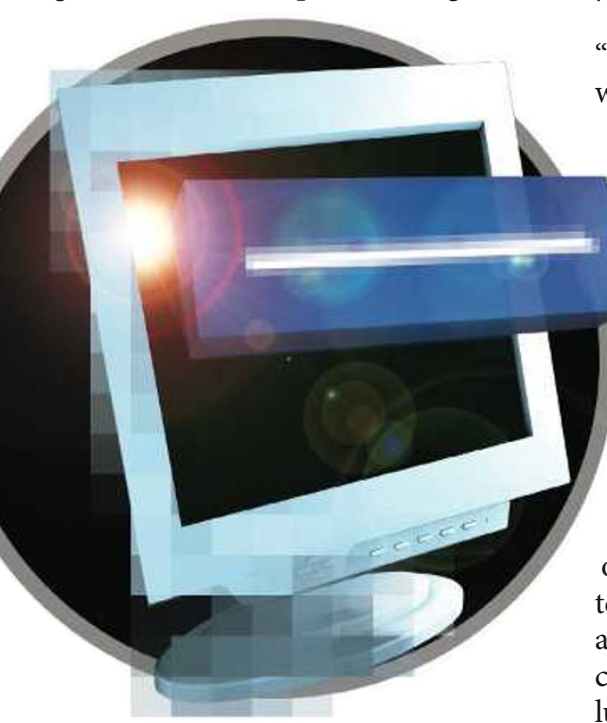

The Mission Controller unbuttoned his waistcoat to let the sweat out. "Initial deployment of all four Tycho Brahe telescopes completed. Beginning sequence for configuration checks. Jim, make sure those eggheads at Goddard are ready.'

Jim looked up from his Sudoku puzzle. "Just did that Frank. They're watching CNN and eating pickled chillies. They asked if we could send over some herring roll-mops."

"Did you remind them of the procedures they should be working?"

"You bet your head, Frank. I told them NASA never lost a telescope in space and we weren't about to lose one on your watch."

"We never lost a telescope?"

Jim returned to his puzzle. "Don't know Frank. I sort of made that up."

Jasper stared in amazement. "I'll discredit your research if we get caught."

"Chill out, dude. We'll be heroes. They'll name stars after us," replied Oddman, the keyboard now an extension of his hands, like a pint of beer.

Jasper flicked a switch. "Houston, we have go for configuration checks." His voice was as a nervous as a window cleaner who didn't like heights. Or water.

"I'm into the James Webb telescope. Uploading software. I am sex on a stick."
"Realigning array to your new coordinates. The heart of the Universe." Jasper wiped his brow.

"Relax dude, we're about to look farther back in time and with greater detail than anyone else, ever."

Jasper checked his monitor. "Receiving combined signal. This had better work or you're off my Christmas-card list."

A voice crackled over the intercom. "Goddard - we're tracking anomalies with the configuration checks."

Jasper reluctantly flicked his switch again. "We're just looking at that, Houston. We'll get back to you."

Jasper and Oddman looked at each other. Jasper looked as though hed had a stroke. On the TV behind them, Pope Albert fingered his ring. "God created Heaven and Earth and all creatures upon it. The scripture evidence is substantial."

Dawkins' incredulous stare could have frozen hell, if it existed. "I'm fed up of arguing the toss with such blinkered sixteenth-century retards as you. You might as well believe we're part of an elaborate computer simulation. Evidence for evolution is beyond substantial - it is overwhelming. Your God isn't dead in the face of this evidence - He never existed!"

Pope Albert waved his hand. "He speaks to me. He wants me for a sunbeam."

Oddman broke the stare. "So what can we see?"

Jasper looked at his monitor. It was largely black, with wisps of swirling silver clouds. The clouds suddenly froze. "That's funny. Look in the centre: a small blue rectangle."

"Jesus! What is that?"

"It's growing." Jasper began tapping at his keyboard. "It's growing faster than the speed of light! Your software is as bugridden as a camel."

"The software's good."

"Well, if it is, that rectangle will reach us in 30 minutes." Jasper shook his head. “There's some faint white lines across the centre."

"I'll enhance it," Oddman said, doubt beginning to creep over him like malaria.

"It's writing."

Oddman slowly read the writing. "Unrecoverable graphics error. Universe $\mathrm{ET}^{\mathrm{Tm}}$ needs to close down."

"What the hell does that mean?"

"Game over, dude."

Paul Grainger is a mid-life crisis waiting to happen. He works in the IT industry to pass the time. He has yet to start a land war in the Middle East. 